\section{Propofol does not affect the canine cardiac con- duction system under autonomic blockade}

\author{
Shigeo Ikeno MD, * \\ Satoshi Akazawa MD, * \\ Reiju Shimizu MD, * \\ Yasushi Nakaigawa MD, * \\ Ryousuke Ishii MD, $\uparrow$ \\ Soichiro Inoue MD, * \\ Masaaki Satoh $M D^{*}$
}

Purpose: To determine the effects of propofol on the cardiac conduction system in dogs with pharmacological autonomic blockade.

Methods: In eight mongrel dogs receiving $6 \mathrm{mg} \cdot \mathrm{kg}^{-1} \cdot \mathrm{hr}^{-1}$ propofol and vecuronium under pharmacological autonomic blockade with atropine and propranolol the infusion rates of propofol were increased from 6, (baseline), to 12,18 and $24 \mathrm{mg} \cdot \mathrm{kg}^{-1} \cdot \mathrm{hr}^{-1}$ at 60 -min intervals. An electrophysiological study assessed sinus rate, sinus node recovery time, corrected sinus node recovery time, intraatrial conduction time, AV nodal effective refractory period. Wenckebach cycle length and AV conduction times. Electrocardiographical variables and arterial pressures were also measured. All measurements were repeated at $30 \mathrm{~min}$ after the beginning of each infusion of propofol.

Results: Propofol did not produce direct effects on the electrophysiological or electrocardiographical variables at any infusion rates. Heart rates did not change at higher infusion rates in the presence of decreases in arterial pressures.

Conclusion: Propofol did not affect the cardiac conduction system in the presence of autonomic blockade. Thus, the direct cardiac effects of propofol do not play a causative role in the genesis of propofol-associated bradyarrhythmias.

Objectif : Déterminer les effets du propofol sur le système de conduction du coeur chez les chiens soumis à un blocage nerveux autonome.

Méthode : L'étude a porté sur huit chiens communs qui ont reçu $6 \mathrm{mg} \cdot \mathrm{kg}^{-1} \cdot \mathrm{hr}^{-1}$ de propofol et du vécuronium sous un blocage pharmacologique nerveux autonome avec de l'atropine et du propranolol. La vitesse de perfusion du propofol a augmenté, passant de 6 , au départ, à 12,18 puis $24 \mathrm{mg} \cdot \mathrm{kg}^{-1} \cdot \mathrm{hr}^{-1}$ à des intervalles de $60 \mathrm{~min}$. Un examen électrophysiologique a permis d'évaluer le rythme sinusal, le temps de récupération sinusale, le temps de récupération sinusale corrigé, le temps de conduction intra-auriculaire, la période réfractaire effective du noeud $A V$, la longueur de la période de Wenckebach et les temps de conduction AV. On a aussi mesuré les variables électrocardiographiques et les pressions artérielles. Toutes les mesures ont été reprises 30 min après le début de chaque perfusion de propofol.

Résultats : Le propofol n'a pas eu d'effet direct sur les variables électrophysiologiques ou électrocardiographiques, résultat valable pour toute vitesse de perfusion. Les fréquences cardiaques n'ont pas changé pendant les perfusions les plus rapides en présence de baisses de pression artérielle.

Conclusion: Le propofol n'a pas affecté la conduction cardiaque en présence d'un blocage nerveux autonome. Par conséquent, les effets directs du propofol sur le coeur n'ont pas eu de rôle causal dans l'apparition des bradyarythmies qui lui étaient associées.

From the Department of Anaesthesiology, ${ }^{*}$ Jichi Medical School, Minamikawachi-machi, Tochigi, Japan and Department of Anaesthesia, $\dagger$ Ohmiya Red Cross Hospital, Yono City, Saitama, Japan.

Address correspondence to: Dr. Shigeo Ikeno, Department of Anaesthesiology, Jichi Medical School, Minamikawachi-machi, Tochigi,

329-0498, Japan. Phone: 81-285-58-7383; Fax: 81-285-44-4108; E-mail; sakazawa@jichi.ac.jp

Accepted for publication November 8, 1998 


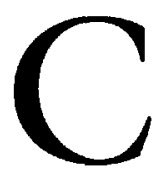

LINICAL use of propofol has been associated with various types of cardiac events such as sinus bradycardia, ${ }^{1,2}$ atrioventricular conduction block, ${ }^{3,4}$ asystole, ${ }^{5-7}$ and the conversion of supraventricular tachycardia to normal sinus rhythm. ${ }^{8}$ These occurred after administration of various drugs or procedures to elicit vagotonic activities and to cause bradyarrhythmias. ${ }^{9,10}$ Because propofol has been shown to exert central vagotonic effects, ${ }^{11,12}$ enhanced cardiac vagal tone could induce the cardiac events described above.

Although some clinical reports support the hypothesis that the direct cardiac effects of propofol do not play a causative role in the genesis of propofol-associated bradyarrhythmias, ${ }^{1-7}$ it remains unclear whether this hypothesis is valid. Furthermore, the cardiac electrophysiological effects of propofol to account for these bradyarrhythmic effects have not been fully examined.

Therefore, we investigated the effects of propofol on sinoatrial node function, intraatrial conduction, atrioventricular nodal refractoriness and atrioventricular conduction times in dogs receiving propofol as a sole anesthetic agent. To evaluate the direct effects of propofol on the cardiac conduction system, this study was performed under pharmacological autonomic blockade.

\section{Methods}

\section{Animal preparation}

The study protocol was approved by the management committee of the Jichi Medical Laboratory of Experimental Medicine, based on the school's Guide for Laboratory Animals, 1993.

Anesthesia was induced in eight mongrel dogs, weighing $13-25 \mathrm{~kg}$, with $10 \mathrm{mg} \cdot \mathrm{kg}^{-1}$ propofol $i v$. The trachea was intubated without neuromuscular blocking agents and ventilation was adjusted to maintain normocapnia with a Harvard pump respirator (R-60, Aika, Co., Ltd.). Carbon dioxide tension was maintained at $35-40 \mathrm{mmHg}$, as assessed by continuous measurement of end-tidal carbon dioxide tension with a calibrated respiratory gas monitor (Model 5250, Ohmeda, Madison, WI, USA) and repetitive analyses of arterial blood gas tensions.

Anesthesia during surgical preparation was maintained with an infusion of propofol at $6 \mathrm{mg} \cdot \mathrm{kg}^{-1} \cdot \mathrm{hr}^{-1}$ and oxygen. All animals were paralyzed with bolus doses of $0.2 \mathrm{mg} \cdot \mathrm{kg}^{-1}$ vecuronium followed by smaller doses, 0.1 $\mathrm{mg} \cdot \mathrm{kg}^{-1}$, as needed. Ten $\mathrm{mg} \cdot \mathrm{ml}^{-1}$ propofol in soybean oil $10 \%$, glycerol $2.25 \%$ and purified egg phosphatide $1.2 \%$ (Diprivan@ 1\%, ZENECA) was employed.

A micromanometer-tipped catheter (7F 45326, Toyoda Instr., Ltd.,Japan) was placed through the left femoral artery into the abdominal aorta to measure systolic, diastolic and mean arterial pressures (SAP, DAP and MAP, respectively). Heart rate (HR) was monitored by electrocardiography (ECG, lead II). A catheter was inserted into the abdominal aorta via the right femoral artery to sample arterial blood for measurement of $\mathrm{pH}, \mathrm{PaCO}_{2}, \mathrm{PaO}_{2}$ and serum $\mathrm{Na}^{+}, \mathrm{K}^{+}$and $\mathrm{Ca}^{2+}$ concentrations (288 Blood Gas System, Ciba Corning). Lactated Ringer's solution was infused at 5 $\mathrm{ml} \cdot \mathrm{kg}^{-1} \cdot \mathrm{hr}^{-1}$ into the left femoral vein throughout the experiment. KCL solution was given to maintain serum $\mathrm{K}^{+}$concentration between 3.5 and 4.5 $\mathrm{mEq} \cdot \mathrm{L}^{-1}$. Body temperature was measured with an esophageal thermistor and maintained at $37-38^{\circ} \mathrm{C}$ using an external heating blanket.

A quadripolar electrode catheter was inserted via the left internal carotid artery and advanced towards the aortic root until a stable His-bundle electrogram (HBE) was obtained as displayed on an oscilloscope. The His-bundle catheter electrodes were connected to a switch box that allowed selection of any combination of two electrodes. The output of the switch box was connected to a preamplifier with a band width cut-off frequency of $40-1000 \mathrm{~Hz}$. The electrodes of a surface ECG (leads II) were connected to another preamplifier with a filter bandwidth of 0.1-120 Hz. The output from each preamplifier and arterial pressure were recorded onto a thermal recorder (8M15, NEC Medical Systems, Ltd., Tokyo, Japan) at a paper speed of $100 \mathrm{~mm} \cdot \mathrm{sec}^{-1}$. Heart rate was measured by counting QRS complexes over $10 \mathrm{sec}$.

The $\mathrm{HBE}$ was recorded at a paper speed of $\mathbf{5 0 0}$ $\mathrm{mm} \cdot \mathrm{sec}^{-1}$ to measure electrophysiological variables with $1.0-\mathrm{msec}$ resolution (Visigraph $5 \mathrm{~L} 37$, NEC Medical Systems, Ltd., Tokyo, Japan). Another quadripolar electrode catheter was inserted into the right atrium via the right femoral vein for atrial pacing. An R-wave-coupled cardiac stimulator (3F6l, NEC Medical Systems, Ltd., Tokyo, Japan) delivering rectangular pulses of 1-msec duration was used for all atrial pacing. The stimulating current used was twice the threshold determined at the baseline state.

\section{Electrophysiological and electrocardiograpbical mea- surements}

Electrophysiological measurements included sinoatrial (SA) conduction time (SACT), sinus node recovery time (SNRT), corrected sinus node recovery time (CSNRT), atrioventricular (AV) nodal effective refractory period (AVNERP), Wenckebach cycle length (WCL) and specialized AV conduction times.

Both AVNERP and SACT were measured by the standard extrastimulus protocol. The right atrium was stimulated at a fixed pacing cycle length of 400 or 360 
TABLE I Effects of propofol infusion rate on arterial pressures and heart rate

\begin{tabular}{lllll}
\hline & \multicolumn{4}{c}{ Infusion rate of propofol $\left(\mathrm{mg}^{\circ} \cdot \mathrm{kg}^{-1} \cdot \mathrm{hr}^{-1}\right)$} \\
& 6 & 12 & 18 & 24 \\
\hline SAP (mmHg) & $175 \pm 35$ & $168 \pm 32$ & $163 \pm 33^{*}$ & $151 \pm 31^{*}$ \\
MAP (mmHg) & $141 \pm 28$ & $136 \pm 25$ & $129 \pm 26^{*}$ & $119 \pm 28^{*}$ \\
DAP (mmHg) & $124 \pm 25$ & $120 \pm 21$ & $112 \pm 24^{\star}$ & $103 \pm 27^{\star}$ \\
HR (bpm) & $140 \pm 15$ & $142 \pm 13$ & $136 \pm 14$ & $132 \pm 17$ \\
\hline
\end{tabular}

Values are mean $\pm \mathrm{SD}$.

$\mathrm{SAP}=$ systolic arterial pressure; $\mathrm{MAP}=$ mean arterial pressure; DAP=diastolic arterial pressure; $H R=$ heart rate.

${ }^{\star} P<0.05$ compared with the value at $6 \mathrm{mg} \cdot \mathrm{kg}^{-1} \cdot \mathrm{hr}^{-1}$.

TABLE II Effects of propofol infusion rate on sinoatrial node function and intraatrial conduction.

\begin{tabular}{|c|c|c|c|c|}
\hline & \multicolumn{4}{|c|}{ Infusion rate of propofol $\left(\mathrm{mg}^{\prime} \mathrm{kg}^{-1} \cdot \mathrm{br}^{-1}\right)$} \\
\hline & 6 & 12 & 18 & 24 \\
\hline & & $565 \pm 57$ & $585 \pm 86$ & $594 \pm 103^{*}$ \\
\hline CSNRT (msec) & $117 \pm 26$ & $115 \pm 32$ & $124 \pm 43$ & $123 \pm 42$ \\
\hline SACT (msec) & $88 \pm 15$ & $87 \pm 12$ & $89 \pm 16$ & $88 \pm 15$ \\
\hline
\end{tabular}

Values are mean $\pm \mathrm{SD}$.

$\mathrm{NRT}=$ sinus node recovery time; $\mathrm{CSNRT}=$ corrected sinus node recovery time; $S A C T=$ sinoatrial conduction time.

${ }^{*} P<0.05$ compared with the value at $6 \mathrm{mg} \cdot \mathrm{kg}^{-1} \cdot \mathrm{hr}^{-1}$

TABLE III Effects of propofol infusion rate on atrioventricular nodal refractoriness

\begin{tabular}{lllll}
\hline & \multicolumn{5}{l}{ Infusion rate of propofol $\left(\mathrm{mg}^{\circ} \cdot \mathrm{kg}^{-1} \cdot \mathrm{hr}^{-1}\right)$} \\
& 6 & 12 & 18 & 24 \\
\hline AVNERP (msec) & $159 \pm 33$ & $166 \pm 31$ & $161 \pm 26$ & $169 \pm 28$ \\
WCL (ms) & $228 \pm 27$ & $221 \pm 24$ & $222 \pm 19$ & $227 \pm 24$ \\
\hline
\end{tabular}

Values are mean $\pm S D$.

AVNERP=atrioventricular nodal effective refractory period; WCL $=$ Wenckebach cycle length.

No significant differences were found in both variables.

msec, chosen to exceed slightly the animal's basic sinus cycle length (BCL). After the last stimulus $\left(S^{1}\right)$ of a train of eight stimuli, a single extrastimulus $\left(S^{2}\right)$ was introduced. The coupling interval $\left(S^{1} S^{2}\right)$ between the last $S^{1}$ and the $S^{2}$ was progressively reduced in 20 msec steps from 380 or $340 \mathrm{msec}$ after every train of stimuli until the right atrial refractory period was reached. Between each sequence, sinus rhythm was maintained for three or four beats. The longest $S^{1} S^{2}$ interval for a stimulus that failed to propagate to the His bundle was defined as the AVNERP. ${ }^{13}$ To determine the SACT, the following intervals were measured from the HBE: $\mathrm{A}^{1} \mathrm{~A}^{2}$ interval=the interval between $S^{1}$ and $S^{2} ; A^{2} A^{3}$ interval=the
TABLE IV Effects of propofol infusion rate on atrioventricular conduction time

\begin{tabular}{lllll}
\hline & \multicolumn{4}{l}{ Infusion rate of propofol $\left(\mathrm{mg}^{-} \mathrm{kg}^{-1} \cdot \mathrm{br}^{-1}\right)$} \\
& 6 & 12 & 18 & 24 \\
\hline AH interval (msec) & $87 \pm 11$ & $86 \pm 10$ & $87 \pm 11$ & $86 \pm 10$ \\
HV interval (msec) & $25 \pm 4$ & $25 \pm 5$ & $25 \pm 5$ & $24 \pm 5$ \\
HS interval (msec) & $99 \pm 13$ & $100 \pm 12$ & $99 \pm 13$ & $99 \pm 13$ \\
\hline
\end{tabular}

Values are mean $\pm S D$.

$\mathrm{AH}$ interval=atrioventricular nodal conduction time; $\mathrm{HV}$ interval=His-Purkinje conduction time;

HS interval=ventricular conduction time.

No significant differences were found in any intervals.

TABLE V Effects of propofol infusion rate on the electrocardiographical variables

\begin{tabular}{lllll}
\hline & \multicolumn{5}{l}{ Infusion rate of propofol $\left(\mathrm{mg}^{\mathrm{kg}} \mathrm{kg}^{-1} \cdot \mathrm{hr}^{-1}\right)$} \\
& 6 & 12 & 18 & 24 \\
\hline RR interval (msec) & $433 \pm 59$ & $428 \pm 41$ & $442 \pm 45$ & $459 \pm 64$ \\
PR interval (msec) & $104 \pm 8$ & $102 \pm 8$ & $102 \pm 8$ & $103 \pm 9$ \\
QRS duration (msec) & $73 \pm 9$ & $73 \pm 9$ & $73 \pm 10$ & $72 \pm 9$ \\
QT interval (msec) & $213 \pm 28$ & $211 \pm 26$ & $214 \pm 23$ & $217 \pm 25$ \\
QTc interval (msec) & $323 \pm 26$ & $322 \pm 31$ & $315 \pm 30$ & $321 \pm 29$ \\
\hline
\end{tabular}

Values are mean $\pm S D$.

QTc interval $=Q T$ interval $/ R R(\mathrm{sec})$.

No significant differences were found in any variables.

length of the postextrasystolic pause (return cycle); $\mathrm{A}^{3} \mathrm{~A}^{4}$ interval=the length of the spontaneous cycle immediately following the return cycle (postreturn cycle). The SACT was defined as the difference between $\mathrm{A}^{2} \mathrm{~A}^{3}$ and $\mathrm{A}^{3} \mathrm{~A}^{4}$ intervals; the values were determined during the plateau zone, where the $A^{2} A^{3}$ intervals remained almost constant allowing estimation of SACT. ${ }^{14}$

The SNRT was measured to assess SA nodal automaticity by right atrial pacing for $30 \mathrm{sec}$ and then halting pacing. The time from the last paced beat to the first sinus escape beat is the SNRT and this value minus BCL prior to onset of each atrial pacing is the CSNRT $^{15}:$ CSNRT $=$ SNRT $-B C L$.

The SNRT and corresponding CSNRT were determined by increasing the atrial pacing rates by $10 \mathrm{bpm}$ from 170 to $230 \mathrm{bpm}$ (seven steps of pacing rates) with a I-min rest period between each pacing interval. The longest of these seven values were considered to be the SNRT (CSNRT) for each infusion of propofol tested.

The WCL was determined by increasing the atrial pacing rates by $5 \mathrm{bpm}$ every 5 -sec stimuli (15-20 paced beats) until second-degree AV block occurred. The incremental atrial pacing was started at a rate of 
$170 \mathrm{bpm}$ in this study, according to the fact that none of dogs exhibited any degree of AV conduction disturbance at least at this pacing rate during the preceding overdrive suppression tests to determine the SNRT and CSNRT.

The AV conduction times measured were A- $\mathrm{H}$ interval (AV nodal conduction time during sinus rhythm), $\mathrm{H}-\mathrm{V}$ interval (His-Purkinje conduction time) and $\mathrm{H}-\mathrm{S}$ interval (total ventricular conduction time). The A-H interval was measured from the beginning of the atrial deflection to the beginning of the His-bundle spike in the HBE. ${ }^{15}$ The $\mathrm{H}-\mathrm{V}$ interval was measured from the beginning of the His-bundle spike to the beginning of the ventricular deflection in the HBE. ${ }^{15}$ The H-S interval was measured from the beginning of the His-bundle spike to the end of the rapid deflection in the HBE..$^{15}$

The RR and PR intervals, QRS duration and QT interval were measured from ECG lead II. The QT interval was corrected for heart rate by dividing the QT interval by the square root of the RR interval to obtain the QTc interval. ${ }^{16}$

\section{Experimental procedure}

Thirty minutes after the completion of all instrumentation, pharmacological autonomic blockade was performed with a combination of $0.5 \mathrm{mg} \cdot \mathrm{kg}^{-1}$ atropine and $1.0-1.5 \mathrm{mg} \cdot \mathrm{kg}^{-1}$ propranolol. ${ }^{17,18}$ The initial doses of both agents were followed by repeated doses of each agent $\left(0.25 \mathrm{mg} \cdot \mathrm{kg}^{-1}\right.$ atropine and $0.5 \mathrm{mg} \cdot \mathrm{kg}^{-1}$ propranolol) ten minutes before measurements at each infusion of propofol (50 to 60 -min intervals).

Ten minutes after the initial autonomic blockade, the values of electrophysiological variables, arterial pressures and heart rate were obtained during an infusion of $6 \mathrm{mg} \cdot \mathrm{kg}^{-1} \cdot \mathrm{hr}^{-1}$ of propofol. Subsequently, the infusion rates of propofol were stepwise increased to 12,18 and $24 \mathrm{mg} \cdot \mathrm{kg}^{-1} \cdot \mathrm{hr}^{-1}$ at 60 -min intervals and all electrophysiological, electrocardiographical and hemodynamic measurements were repeated at $30 \mathrm{~min}$ after the beginning of each infusion of propofol.

\section{Statistical analysis}

All values are expressed as mean \pm SD. Statistical analysis was performed using analysis of variance (ANOVA) with repeated measures, followed by Fisher's protected least significant difference (PLSD). $P<0.05$ was considered statistically significant.

\section{Results}

Changes in arterial pressures and heart rate

Heart rates did not change in the presence of decreases in SAP, DAP and MAP at infusion rates of 18 and $24 \mathrm{mg} \cdot \mathrm{kg}^{-1} \cdot \mathrm{hr}^{-1}$ (Table I).
Electrophysiological and electrocardiographical effects The effects of propofol on SA node function, intraatrial conduction and AV nodal refractoriness are shown in Table II and III. Propofol prolonged the SNRT at 24 $\mathrm{mg} \cdot \mathrm{kg}^{-1} \cdot \mathrm{hr}^{-1}$, while the CSNRT remained unchanged. The SACT, AVNERP and WCL also remained unchanged at any infusion rates.

Propofol did not affect specialized AV conduction times: the A-H, H-V and $\mathrm{H}-\mathrm{S}$ intervals remained unchanged (Table IV).

Small increases in the RR intervals coincided with the insignificant decreases in heart rate at 18 and 24 $\mathrm{mg} \cdot \mathrm{kg}^{-1} \cdot \mathrm{hr}^{-1}$. There were no changes in the PR interval, QRS duration, and QT and QTc intervals at any infusions of propofol (Table V).

\section{Discussion}

We found that propofol did not exert direct effects on $\mathrm{SA}$ node function, intraatrial conduction, AV nodal refractoriness or AV conduction times at any infusion rates under autonomic blockade. Electrocardiographical variables remained unchanged. Heart rates did not change in the presence of decreases in arterial pressures at higher infusion rates. Thus, the direct cardiac effects of propofol do not play a causative role in the development of bradyarrhythmias. Our results are not consistent with those obtained in dogs under pharmacological autonomic blockade. ${ }^{19}$ In that study the doses of autonomic blocking drugs may have been too low. Thus, some of the changes they detected may have been due to a central vagotonic effect of propofol. Comparable electrophysiological studies of propofol with this study using the heart in situ have not been performed.

Propofol-associated bradyarrhythmias have been associated with situations known to elicit vagotonic stimuli such as succinylcholine, ${ }^{2,3,7}$ neostigmine, ${ }^{3}$ and fentany $1^{1,4-7}$ administration. Therefore, the cardiac vagal tone may have been enhanced in the presence of these vagotonic stimuli in the documented cases of bradyarrhythmias. The administration of atropine has been shown to mitigate or effectively reverse these events. ${ }^{1-7}$

In our earlier study in dogs, ${ }^{20}$ the total serum concentration of propofol increased from $2.9 \pm 0.3$ to $11.5 \pm 0.1 \mu \mathrm{g} \cdot \mathrm{ml}^{-1}$ after graded infusion rates of propofol $\left(6,9,12,15,18\right.$ and $\left.21 \mathrm{mg} \cdot \mathrm{kg}^{-1} \cdot \mathrm{hr}^{-1}\right)$ at 30 min intervals; the peak value of $11.5 \mu \mathrm{g} \cdot \mathrm{ml}^{-1}$ is about three times as high as those achieved during maintenance of an adequate level of clinical anesthesia (4 - 5 $\left.\mu \mathrm{g} \cdot \mathrm{ml}^{-1}\right) .^{21}$ Therefore, the serum levels of propofol probably reached much higher levels in this study than those in our earlier study, ${ }^{20}$ because of the prolonged perfusion $(60 \mathrm{~min})$ and the higher final infusion rate (24 $\mathrm{mg} \cdot \mathrm{kg}^{-1} \cdot \mathrm{hr}^{-1}$ ) employed. 
Graded increases in propofol infusion rates did not affect SA nodal automaticity in this study: the CSNRT remained unchanged; the prolongation in SNRT at 24 $\mathrm{mg} \cdot \mathrm{kg}^{-1} \cdot \mathrm{hr}^{-1}$ may have been due to a decrease in spontaneous heart rate, because SNRT has been shown to be proportional to the control sinus cycle length. ${ }^{13}$ In addition, propofol did not prolong sinoatrial or AV nodal conduction time (SACT and A-H interval, respectively) at any infusion rates. The lack of direct negative chronotropic and dromotropic effects of propofol makes it likely that propofol-associated bradyarrhythmias could be attributed to the central vagotonic effects of propofol.

We also found that propofol did not prolong the AV nodal effective refractory period (AVNERP) and Wenckebach cycle length (WCL) in this study. Therefore, propofol does not possess properties to suppress AV nodal-dependent supraventricular tachycardias directly. The lack of changes in electrocardiographical variables appears to reflect an absence of direct electrophysiological effects of propofol on the cardiac conduction system.

Our results further indicate that propofol should exert neither direct arrhythmogenic nor direct antidysrhythmic effects on the heart. Consequently, the development of bradyarrhythmias and the suppression of supraventricular tachycardia are probably mediated by indirect effects of propofol in depressing sympathetic outflow, ${ }^{11,12}$ enhancing vagal tone, ${ }^{11,12}$ altering the baroreceptor sensitivity, ${ }^{22-26}$ and effects which may be additive or synergistic in nature.

This study lacks awake values obtained in the absence of basal propofol-vecuronium anesthesia. Basal propofol presumably exerted only minimal effects on the heart, because heart rate showed higher values of 110-130 bpm before autonomic blockade. Alvarez et al. found no electrophysiological effects of vecuronium on normal and denervated dog hearts. ${ }^{27}$ Therefore, the addition of graded infusions of propofol up to $24 \mathrm{mg} \cdot \mathrm{kg}^{-1} \cdot \mathrm{hr}^{-1}$ enabled us to detect and evaluate the dose-related direct electrophysiological effects of propofol in this study.

In summary, propofol, even at doses greater than those used in clinical practice, did not exert direct effects on the SA node function, intraatrial conduction, AV nodal refractoriness and AV conduction times in dogs with pharmacological autonomic blockade. Thus, the direct cardiac effects of propofol do not play a causative role in the genesis of propofol-associated bradyarrhythmias.

\section{Acknowledgments}

We thank K. Nozawa and H. Yoshida (NEC Medical
Systems, Utsunomiya, Japan) for their technical assistance in this study. We also thank Mrs. H. Kuramochi for her help in the preparation of this manuscript.

\section{References}

1 Thomson SJ, rate PM. Bradycardia after propofol infusion (Letter). Anaesthesia 1987; 42: 430.

2 Baraka A. Severe bradycardia following propofol-suxamethonium sequence. Br J Anaesth 1988; 61: 482-3.

3 James MFM, Reyneke CJ, Whiffler $K$. Heart block following propofol: a case report. Br J Anaesth 1989; 62: 213-5.

4 Ganansia $M-F$, Francois TP, Ormezzano X, Pinaud $M L$, Lepage J-X. Atrioventricular Mobitz I block during propofol anesthesia for laparoscopic tubal ligation. Anesth Analg 1989; 69: 524-5.

5 Dorrington KL. Asystole with convulsion following a subanaesthetic dose of propofol plus fentanyl. Anaesthesia 1989; 44: 658-9.

6 Guise PA. Asystole following propofol and fentanyl in an anxious patient. Anaesth Intensive Care 1991; 19: $116-8$.

7 Egan TD, Brock-Utne JG. Asystole after anesthesia induction with a fentanyl, propofol, and succinylcholine sequence. Anesth Analg 1991; 73: 818-20.

8 Hermann $R$, Vettermann J. Change of ectopic supraventricular tachycardia to sinus rhythm during administration of propofol. Anesth Analg 1992; 75: 1030-2.

9 Rogers $M C$. Diagnosis and treatment of intraoperative cardiac dysrhythmias. In: Miller RD (Ed.). Anesthesia, 2nd ed. New York: Churchill Livingstone Inc., 1986: 499-521.

10 Atlee JL III, Bosnjak ZJ. Mechanisms for cardiac dysrhythmias during anesthesia. Anesthesiology 1990; 72: 347-74.

11 Cullen PM, Turtle M, Prys-Roberts C, Way WL, Dye J. Effect of propofol anesthesia on baroreflex activity in humans. Anesth Analg 1987; 66: 1115-20.

12 Deutschman CS, Harris AP, Fleisher LA. Changes in heart rate variability under propofol anesthesia: a possible explanation for propofol-induced bradycardia. Anesth Analg 1994; 79: 373-7.

13 Josephson ME. Clinical Cardiac Electrophysiology: Techniques and Interpretations, 2nd ed. Philadelphia: Lea \& Febiger, 1993; 22-116.

14 Kirkorian G, Touboul P, Atallah G, Moleur P, Zuloaga $C D$. Premature atrial stimulation during regular atrial pacing: a new approach to the study of the sinus node. Am J Cardiol 1984; 54: 109-14.

15 Fogoros $R N$. Principles of the electrophysiology study. In: Fogoros RN (Ed.). Electrophysiologic Testing in the Evaluation and Therapy of Cardiac Arrhythmias. Boston: Blackwell Scientific Publications, 1991; 37-101. 
16 Bazett HC. An analysis of the time-relations of electrocardiograms. Heart 1920; 7: 353-70.

17 Zipes DP, Fischer JC. Effects of agents which inhibit the slow channel on sinus node automaticity and atrioventricular conduction in the dog. Circ Res 1974; 34: 184-92.

18 Schwartz JB, Shen C, Garcia J, Capili H, Sniezek $M$. Influence of autonomic blockade and aging on AV conduction and responses to verapamil in the beagle. J Gerontol A Biol Sci Med Sci 1995; 50A: M83-90.

19 Colson $P$, Barlet $H$, Roquefeuill B, Eledjam JJ. Mechanism of propofol bradycardia (Letter). Anesth Analg 1988; 67: 906-7.

20 Nakaigawa $r$, Akazawa S, Shimizu $R$, Ishii $R$, Tamato $R$. Effects of graded infusion rates of propofol on cardiovascular haemodynamics, coronary circulation and myocardial metabolism in dogs. Br J Anaesth 1995; 75: 616-21.

21 Cockshott ID. Propofol ('Diprivan') pharmacokinetics and metabolism-an overview. Postgrad Med J 1985; 61(Suppl 3): 45-50.

22 Blake DW, Jover B, McGrath BP. Haemodynamic and heart rate reflex responses to propofol in the rabbit. $\mathrm{Br}$ J Anaesth 1988; 61: 194-9.

23 Rocchiccioli C, Saad MAA, Elghozi J-L. Attenuation of the baroreceptor reflex by propofol anesthesia in the rat. J Cardiovasc Pharmacol 1989; 14: 631-5.

24 Kamijo $\Upsilon$, Goto H, Nakazawa K, Benson KT, Arakawa $K$. Arterial baroreflex attenuation during and after continuous propofol infusion. Can J Anaesth 1992; 39: 987-91.

25 Ebert TJ, Muzi M. Propofol and autonomic reflex function in humans. Anesth Analg 1994; 78: 369-75.

26 Sellgren J, Ejnell $H$, Elam $M$, Pontén J, Wallin BG. Sympathetic muscle nerve activity, peripheral blood flows, and baroreceptor reflexes in humans during propofol anesthesia and surgery. Anesthesiology 1994; 80: 534-44.

27 Alvarez L, Escudero C, Silva L, Castillo-Olivares JL. Electrophysiological effects of atracurium and vecuronium on normal and denervated hearts. J Cardiothorac Vasc Anesth 1992; 6: 304-7. 